\title{
Aportes para una historia de la Revolución Libertadora en Mendoza
}

\author{
Yamile Álvarez \\ Facultad de Filosofía y Letras \\ (Universidad Nacional de Cuyo) \\ yamileal63@gmail.com
}

\section{Resumen}

El 16 de septiembre de 1955 se produjo en nuestro país la autodenominada Revolución Libertadora, que puso fin al gobierno constitucional de Juan Domingo Perón. Este acontecimiento marca un punto de inflexión en la historia argentina ya que dio inicio a un período de gran inestabilidad política e institucional caracterizado por la proscripción del peronismo y la alternancia de gobiernos militares y pseudos-democráticos.

Debido a su importancia este hecho histórico ha sido objeto de numerosas e importantes investigaciones, realizadas por especialistas argentinos y extranjeros, pero haciendo hincapié fundamentalmente en el orden nacional y descuidando lo acontecido en los espacios provinciales.

Es por ello que a través de este trabajo, me propuse reconstruir los acontecimientos históricos que tuvieron lugar en Mendoza desde el estallido del movimiento revolucionario hasta la renuncia del general Perón, y determinar la contribución de ellos en el éxito final del movimiento revolucionario.

\section{Palabras claves}

Historia Argentina, Historia Regional, Peronismo, Proscripción, Revolución Libertadora

\begin{abstract}
The Revolution of the 16 September 1955, that ended the second government of General Perón, gave beginning to a period of great political and institutional instability characterized by the proscription of the Peronism and the rotation of military and pseudos-democratic governments.

Due to its importance, this numerous event has been object of important investigations, realised by Argentine and foreign specialists, who make emphasis in the national order essentially.

It is therefore that some years ago we approached this thematic, at provincial level, and we set out to reconstruct the historical events that had taken place in Mendoza during the denominated "Liberty Revolution" and to determine the contribution of them in the final success of the revolutionary movement.
\end{abstract}

\section{Keywords}

Argentina History, Regional History, Peronism, Proscription, Liberty Revolution

Esta obra está sujeta a la Licencia Reconocimiento-NoComercial-CompartirIgual 4.0 Internacional de Creative Commons. http://creativecommons.org/licenses/by-nc-sa/4.0/ 


\section{Introducción}

El 16 de septiembre de 1955 se produjo en nuestro país la autodenominada Revolución Libertadora, que puso fin al gobierno constitucional de Juan Domingo Perón. Este acontecimiento marca un punto de inflexión en la historia argentina ya que dio inicio a un período de gran inestabilidad política e institucional caracterizado por la proscripción del peronismo y la alternancia de gobiernos militares y pseudos-democráticos.

Debido a su importancia este hecho histórico ha sido objeto de numerosas e importantes investigaciones, realizadas por especialistas argentinos y extranjeros, pero haciendo hincapié fundamentalmente en el orden nacional y descuidando lo acontecido en los espacios provinciales. ${ }^{1}$

Es por ello que a través de este trabajo, me propuse reconstruir los acontecimientos históricos que tuvieron lugar en Mendoza desde el estallido del movimiento revolucionario hasta la renuncia del general Perón y su posterior consolidación, y confirmar o no, si la contribución de ellos fue determinante en el éxito final de la Revolución Libertadora.

Para alcanzar este objetivo, y debido a la ausencia de investigaciones sobre el tema, he recurrido al análisis de los periódicos locales editados en el año $1955 \mathrm{y}$, al testimonio de algunos de los protagonistas, civiles y militares, de estos hechos históricos que aún vivían y estaban dispuestos a relatarnos sus experiencias. ${ }^{2}$

El artículo está organizado en tres apartados. El primero describe el ambiente que se vivía en Mendoza en los meses previos al estallido revolucionario; el segundo reconstruye el desarrollo de los acontecimientos desde el inicio del movimiento hasta la caída del gobierno provincial, y el último se ocupa de las tratativas para la conformación de un gobierno nacional provisorio en Mendoza, cosa que finalmente

\footnotetext{
${ }^{1}$ En Mendoza existe muy poca bibliografía de carácter general que haga referencia a este período de la historia provincial. Estas son: Adolfo Cueto Aníbal Romano y Pablo Sacchero. Historia de Mendoza. Mendoza, Los Andes, 1995. Obra de divulgación, publicada por el Diario Los Andes en 28 fascículos. El período que nos ocupa es tratado sintéticamente en el fascículo 23, haciendo hincapié fundamentalmente en los aspectos institucionales. Diario Los Andes. Cien años de vida mendocina, Mendoza, 1982. Obra conmemorativa del centenario del Diario Los Andes, en donde se describen brevemente, por años, los principales aspectos de la vida mendocina entre 1882 y 1992. Junta de Estudios Históricos de Mendoza. Historia Contemporánea de Mendoza a través de sus gobernadores. $T$ I (1932-1966). Mendoza, 1996. Se trata de una compilación de artículos en donde se reseña la labor gubernativa de los gobernadores elegidos en forma democrática. Benito Marianeti. Las luchas sociales en Mendoza. Mendoza, Ed. Cuyo, 1970. Se trata de una reducida crónica de las luchas del movimiento obrero mendocino desde la óptica de un dirigente comunista. Su exposición es sumamente desordenada. Pedro S. MARTínez. Historia de Mendoza. Buenos Aires, Plus Ultra, 1979. Esta obra nos ofrece un panorama histórico, político y cultural de Mendoza, desde la fundación hasta 1976. Arturo Roig y otros, (compiladores,. Mendoza, a través de su historia. Mendoza, Book, 2004.

${ }^{2}$ Como sostienen Laura Benadiba y Daniel Plotinsky en su libro De entrevistadores y relatos de vida. Introducción a la Historia Oral. Buenos Aires, Imago Mundi, 2005, p.13: "Si bien las fuentes orales tienen validez informativa y nos permiten conseguir testimonios reveladores sobre acontecimientos pasados, lo más singular y precioso es que introducen la subjetividad del hablante. Y en ese sentido, la subjetividad (lo que los protagonistas creen) es un hecho histórico, tanto como lo que realmente sucedió".
} 


\title{
Yamile Álvarez
}

no se llevó a cabo, y las primeras medidas adoptadas por el gobierno de la intervención federal.

\section{Mendoza en los meses previos al estallido}

En el transcurso de las dos primeras presidencias de Juan D. Perón, la provincia de Mendoza fue gobernada por Faustino Picallo-Rafael Tabanera (1946-1949), Blas Brísoli-Rodolfo Schmidt (1949-1952) y Carlos Evans-Juan de la Torre (1952-1955), todos ellos pertenecientes al partido peronista. En los tres casos ganaron las elecciones con un amplio caudal de votos. Estas administraciones se caracterizaron por la realización de numerosas obras públicas y en general son calificadas, por oficialistas y opositores, como honestas y respetables. Al respecto Carlos Aguinaga, uno de los principales dirigentes del partido Demócrata de ese entonces opinaba:

\begin{abstract}
Los gobiernos de Mendoza fueron, dentro de la ubicación general, comprometidos con la política del gobierno nacional, pero en el conjunto si se analiza la falta de garantías, la agresión, el populismo, en Mendoza no fue así. ... si bien hicieron política económica y social impuesta desde Buenos Aires, lo hicieron con equilibrio y moderación, desde luego que hubieron persecuciones, pero muy limitadas a los sectores dirigentes de los partidos muy comprometidos de la oposición. Pero como conjunto de la colectividad mendocina, yo creo que Mendoza, es uno de los lugares donde menos se sufrió el cambio que se pretendía hacer desde Buenos Aires. El balance fue positivo. ${ }^{3}$
\end{abstract}

En forma similar se manifestaba Ernesto Corvalán Nanclares, un importante dirigente peronista de aquella época:

En términos amplios y generales, hay un calificativo que se les puede dar a esos gobiernos, en el sentido que todos fueron gobiernos honestos, que trataron de desarrollar políticas importantes en la provincia de Mendoza. ${ }^{4}$

Los meses previos al estallido de la Revolución Libertadora se caracterizaron por el endurecimiento de las relaciones entre el gobierno de Juan D. Perón y la Iglesia Católica. Atentados, manifestaciones y numerosas detenciones de civiles y religiosos se produjeron en Buenos Aires y el resto del país.

Estos acontecimientos tuvieron amplia difusión, aunque muy parcializada, en los periódicos oficialistas locales "Los Andes" y "La Libertad", y en los ámbitos político y legislativo era donde tenían mayor resonancia.

La crónica local da cuenta de que el 25 de mayo de 1955, con el auspicio de la Acción Católica Argentina, el obispo diocesano Monseñor Alfonso Buteler ofreció una misa vespertina en la Basílica de San Francisco para rogar por la patria. El templo se colmó de fieles y por altoparlantes instalados en la calle se hacía referencia a la situación por la que pasaba la Iglesia en esos momentos. Una vez concluida la

\footnotetext{
${ }^{3}$ Dr. Carlos Aguinaga, dirigente demócrata, entrevista realizada en 1990.

${ }^{4}$ Dr. Ernesto Corvalán Nanclares, dirigente peronista, entrevista realizada en 1990.
} 


\section{Aportes para una historia de la Revolución Libertadora en Mendoza}

ceremonia religiosa se entonó el Himno Nacional en el atrio de la iglesia, y se organizó una manifestación pública que avanzó hacia el centro de la ciudad. En el trayecto un cordón policial trató de detener a los manifestantes, ya que no contaban con el permiso correspondiente. Como no lo lograron, fueron interceptados por una autobomba del cuerpo de bomberos que lanzó chorros de agua sobre el público produciéndose la dispersión. Como consecuencia de estos hechos varias personas fueron detenidas ${ }^{5}$ y condenadas a 15 y 10 días de prisión por infringir la ley nacional 14.400 que prohibía las reuniones públicas. Este acontecimiento fue repudiado por el partido peronista mendocino, la CGT regional Mendoza y los bloques de diputados y senadores peronistas provinciales.

El punto culminante de la tensión Iglesia católica-Estado peronista se produjo en junio cuando con motivo de la procesión de Corpus Christi realizada en la Capital Federal, se acusó a miembros de la Iglesia de quemar una bandera argentina. A esto le sucedió el bombardeo de la Plaza de Mayo por parte de la aviación naval, que dejó un saldo de cientos de civiles heridos y muertos. En respuesta a ello, partidarios del gobierno incendiaron iglesias y locales de partidos opositores.

Estos acontecimientos fueron reflejados en forma amplia por la prensa local. "La Libertad" en su edición del 12 de junio titulaba "Quemaron una Bandera Argentina y la reemplazaron por la del Vaticano. Traidores", y el 13 de junio "Buscaba mártires la criminal comparsa de los curas Tato y Novoa. Bárbaros! Responde el país. Un plan urdido fría y satánicamente. Extranjeros y Judas de la Patria componían la asesina procesión".

El gobierno provincial, el partido peronista, la Cámara de diputados y senadores, la Federación Económica de Mendoza, la Universidad Nacional de Cuyo, las municipalidades y todos gremios y sindicatos de la provincia condenaron los hechos y expresaron su adhesión a la política presidencial. El 14 de junio la CGT regional Mendoza llevó a cabo un paro general de actividades que abarcó todas las ramas de la industria y el comercio.

A raíz del alzamiento militar se repitieron las concentraciones populares en adhesión a Perón, las declaraciones de condena y un nuevo paro general de la CGT regional que se realizó el 17 de junio.

Mientras tanto los grupos católicos optaron por armarse con lo que tenían a mano y hacer guardias en las distintas iglesias de Mendoza para evitar que ocurrieran en la provincia los mismos desmanes que en la Capital.

En el ámbito militar la Agrupación de Montaña Cuyo y la IV Brigada Aérea se mantuvieron leales al gobierno provincial y nacional.

\footnotetext{
${ }^{5}$ Los detenidos fueron Eligio Moreira Varela, cura párroco de San José; Dante Picote, Cura párroco de Godoy Cruz; Heriberto Ferreira, sacerdote de la Iglesia de La Merced; y los ciudadanos Armando Juan Gei, Augusto E. Moscoso, José Donati, Genaro Príncipe, José Jiménez, Marcelino Castillo; Alberto A. Ruíz; Andrés Flores, José Correa Llano, José Luis Rúpolo, Carlos Ángel Arandina, Ángel Héctor Marione; Amadeo Cicchitti, Enzo Santoni, miembro de la mesa directiva de la UCR y Pascual Illanes ex diputado provincial por la UCR.
} 


\section{Yamile Álvarez}

En los meses de julio y agosto solo se registraron algunos ataques con bombas de alquitrán en los frentes de algunos locales del partido peronista. Fuera de estos hechos aislados, no se percibía un ambiente revolucionario a nivel popular, pero existían contactos y planes conspirativos entre las principales figuras de los partidos radical y demócrata.

\section{La Revolución Libertadora en Mendoza}

El golpe militar que estalló en Córdoba el 16 de septiembre de 1955, en Mendoza contó con la participación de civiles, pertenecientes a los partidos Demócrata y Radical, y de militares, jefes y oficiales de la Agrupación de Montaña Cuyo. Sin embargo, la figura más relevante llegó desde Buenos Aires para organizar el levantamiento y fue el general Julio Lagos.

La personalidad de este militar nos resulta bastante contradictoria y difícil de definir, ya que a través de diversos testimonios sabemos que fue uno de los primeros y más entusiastas partidarios de Perón. Incluso fue el primer militar afiliado al Partido Peronista, lo cual le valió las críticas de muchos colegas que luego se mantendrían leales al gobierno del general Perón, y fue acreedor de la medalla a la lealtad peronista. A modo de justificación una crónica periodística posterior a la revolución sostenía:

\footnotetext{
el general Lagos tomó su decisión impulsado por los vandálicos hechos ocurridos en la Capital Federal, quema de las Iglesias y otros desmanes, luego del fracasado intento del 16 de junio. Apersonado al día siguiente al entonces ministro de Ejército, general Lucero, le hizo conocer sus ideas y ante él fijó su posición. El general Lucero le prometió entonces que todas esas cuestiones serían solucionadas.

Tales planteos, se nos dice, no tuvieron eco y, por el contrario, significaron el alejamiento del general Lagos del Comando del II Ejército y el posterior anuncio periodístico de su pase a retiro. ${ }^{6}$
}

Los acontecimientos que tuvieron a Mendoza como protagonista comenzaron a desarrollarse el 13 de septiembre cuando el Mayor Guevara se puso en contacto con el general Lagos y le comunicó que, bajo la jefatura del general Eduardo Lonardi, el 16 de septiembre estallaría una revolución en Córdoba. Su misión era sublevar el Segundo Ejército con sede en la ciudad de San Luis, del cual había sido comandante hasta poco tiempo antes, para evitar que estas fuerzas fueran utilizadas para reprimir a Córdoba.

Esa misma noche Lagos partió en auto hacia Mendoza junto con su hermano Carlos y el Dr. Bonifacio del Carril. Al día siguiente, cerca del mediodía, llegaron a las Sierras de San Luis y en la Cuesta del Gato, se entrevistaron con el general Eugenio Arandía, que era jefe del Estado Mayor del Segundo Ejército. Las noticias que les comunica no eran muy buenas: se había hecho cargo del comando el general José María Epifanio Sosa Molina, enviado por el ministro Lucero, con la misión de investigar las posibles

\footnotetext{
${ }^{6}$ Proceso, Mendoza, 6/10/ 1955, p. 2.
} 
conexiones con el fallido levantamiento del general Videla Balaguer. Los oficiales estaban muy vigilados y los contactos revolucionarios se habían roto. De allí que lo mejor, según Arandía, era seguir viaje a Mendoza y ponerse en contacto con el teniente coronel Fernando Elizondo para restablecer los hilos conspirativos.

Lagos y sus acompañantes partieron inmediatamente rumbo a Mendoza, a donde llegaron el 15 de septiembre. Se dirigieron a la casa de la familia Arizu, en donde se encontraron con el teniente coronel Elizondo, quien le manifestó al general su adhesión a la revolución, pero bosquejó un panorama bastante pesimista ya que las tropas estaban dispersas en la montaña, en las provincias de Mendoza y San Juan, por lo que prácticamente era imposible reunirlas y comunicarse con los jefes que debían sublevarlas. De todas formas se comprometió a intentarlo.

Con este fin, esa noche se puso en contacto con el ex teniente de aviación Ricardo Ahualli, dado de baja por su participación en la revolución de 1951, y le ordenó que se comunicara en Campo de los Andes con el coronel Cecilio Labayrú, y en San Juan con el teniente coronel Fonseca, para notificarles de la presencia del general Lagos en Mendoza y del estallido de la revolución en Córdoba. Ambos debían manifestar cual era su posición frente al movimiento revolucionario.

Ahualli envió dos emisarios para cumplimentar este pedido y en ambos casos las respuestas fueron afirmativas. También se le ordenó averiguar cuál era la posición de la Base Aérea, por lo que tomó contacto con el capitán Mario Saccone. La contestación fue que tanto él, como el primer teniente Galioti y varios oficiales más se hacían responsables de que la IV Brigada Aérea se volviera rebelde a pesar de que los suboficiales habían sido armados para mantener la lealtad de la base al gobierno. El 16 de septiembre en Mendoza todo comenzó normalmente. Sin embargo, los civiles revolucionarios fueron alertados de lo que iba a suceder, por lo que se hallaban a la expectativa esperando el momento para actuar.

\begin{abstract}
Me encontré, dice Roberto Videla Zapata, en la entrada del Banco Mendoza en la mañana temprano a eso de las 8:30 con Roberto Norton que estaba vinculado con el movimiento revolucionario... Me dice, acá han llegado Lagos, con el hermano y Bonifacio del Carril y están en la casa del Turco Roth que estaba a una cuadra de mi casa, en la esquina N.O. de la calle Arístides Villanueva y Huarpes, y necesitan con urgencia una buena radio, así que encargate de buscarles una buena radio y llevásela. Yo la radio que tenía era muy pobre, así que me fui a la casa de Daniel Larriqueta, que tenía una muy buena radio, le expliqué sucintamente que la necesitaba, me la dió y fui a la casa donde estaba Lagos, con el hermano y Bonifacio del Carril que había sido compañero mío de la facultad en Buenos Aires y yo le entregué en propias manos la radio y me puse a disposición de ellos. ${ }^{7}$
\end{abstract}

Una vez que el general Lagos se instaló en la casa de Roth, Bonifacio del Carril se dirigió a la casa del Dr. Vera Vallejo en busca de noticias. Allí fue informado de que el general Lonardi se había sublevado en Córdoba, y que se había ordenado a las fuerzas de Cuyo marchar rumbo a Córdoba para participar de la represión. Para

\footnotetext{
${ }^{7}$ Roberto Videla Zapata, dirigente demócrata, entrevista realizada en Mendoza, noviembre de 1990.
} 


\section{Yamile Álvarez}

organizar la marcha había llegado a Mendoza procedente de San Luis el general José Epifanio Sosa Molina. Se había dispuesto el requisamiento de todos los camiones de la Provincia. Por su parte Elizondo se había comunicado con los oficiales de más confianza y pedía a Lagos instrucciones. ${ }^{8}$

Mientras tanto la crónica periodística describía de la siguiente manera el primer día de la revolución:

Una jornada normal de trabajo se desarrolló ayer en Mendoza, sólo alterada en la medida que los acontecimientos que son de dominio público pudieron repercutir en algunos sectores. La ciudad amaneció tranquila, notándose algún movimiento anormal alrededor de las 10, en que los bancos suspendieron sus actividades al público y algunos colegios regidos por instituciones religiosas dieron asueto a sus alumnos. El resto de las escuelas provinciales y otros institutos desarrollaron sus clases normalmente.

... Los comercios funcionaron a plena normalidad cerrando a mediodía a la hora acostumbrada y reabriendo sus puertas en horas de la tarde, según el horario establecido. El cierre por la tarde se adelantó en una hora, atendiendo órdenes impartidas en ese sentido y relacionadas con el toque de queda ordenado por las autoridades. En la CGT, todo el día se registró movimiento de dirigentes, los que acudían a recibir órdenes. En la delegación regional Mendoza, según se nos manifestó, se realizaron algunas asambleas de orden interno durante la jornada, impartiéndose directivas recibidas de la central nacional obrera en el sentido de que los trabajadores debían abstenerse de toda clase de manifestaciones y acudir a sus tareas habituales. ${ }^{9}$

Cabe destacar que, con motivo de la implantación del estado de sitio por parte del gobierno nacional, se dispuso en la provincia el "toque de queda" a partir de las 18:30, por lo que todas las reuniones quedaron suspendidas a partir de esa hora. La policía desde temprano mantuvo vigilancia en los servicios esenciales como centros de comunicaciones, emisoras radiales, diarios, etc.

En el seno del gobierno provincial, el entonces diputado peronista Alberto Serú García nos relató cómo se vivía esta situación:

cuando se produjo el movimiento, en Mendoza se realizan reuniones a nivel gubernamental. Los primeros momentos la situación es confusa. ... a posteriori con motivo de las radios rebeldes que se empezaron a escuchar, se empezó a tener la sensación de que el movimiento era más fuerte, mas serio... Con un grupo de amigos personalmente le digo al gobernador que visitaría a los jefes del comando militar que estaban en aquel entonces en la calle Patricias Mendocinas. ... El coronel que nos atendió nos dijo que estimaba que no había mayores problemas, que la unidad de batalla bajo el mando del general local respondía a sus mandos naturales, es decir al gobierno constitucional. No obstante eso, como advertíamos movimiento de dirigentes políticos en la calle y el proceso iba avanzando, yo le planteé al gobernador Evans, la conveniencia de ordenar la detención de todos los dirigentes políticos de la oposición. Propuse que todos los dirigentes políticos de la oposición, que no serían más de 200, fueran detenidos

\footnotetext{
${ }^{8}$ El ex primer teniente Ahualli, en una entrevista realizada en 1990, nos refirió que los civiles que rodeaban a Lagos opinaban que el general debía hacerse cargo en el camino de la columna que avanzaba hacia San Luis. Tanto Ahualli como el ex primer teniente Fonseca que lo acompañaban, le hicieron ver que en el camino había varios puestos de guardia y que iba a ser imposible sortearlos a todos con éxito. Es por ello que el general Lagos decidió esperar en Mendoza el regreso de las tropas. ${ }^{9}$ Los Andes, Mendoza, 17/09/1955, p.4.
} 
y concentrados en el Hotel de Villavicencio, que en ese momento estaba en reparaciones. La idea no prosperó en ese momento, parecía exagerada. ${ }^{10}$

En el ámbito militar, la Agrupación de Montaña Cuyo estaba al mando del general Héctor Raviolo Audisio, y respecto a la situación que se vivía en aquellos días, el entonces capitán Horacio Farmache nos decía:

\begin{abstract}
A los pocos días (principios de septiembre) yo como oficial de operaciones tomé conocimiento de algunas actitudes que evidenciaban que había gente que estaba conspirando, no tanto a nivel militar porque nosotros en aquel entonces éramos muy respetuosos de nuestros camaradas, es decir que la información que nos llegaba en todos los casos por la vía militar se refería a actividades conspirativas de tipo civil, es decir gente que estaba comprometiéndose en una actitud que no era indudablemente constitucional, ni legal. En esos días se implantó el plan Conintes, abreviatura que significaba conmoción interna del Estado que le daba al Comando de la Agrupación de Montaña Cuyo responsabilidades muy concretas en el manejo del orden público.

Ya con la implantación del plan CONINTES, el comando empezó a recibir información del servicio de inteligencia y así se tuvo un cuadro de situación de que indudablemente había un proceso de conspiración en marcha, no obstante no hubo motivo para tomar ninguna medida en particular ni dentro del ámbito militar, ni tampoco dentro del ámbito civil porque acá en Mendoza la repercusión era muy relativa. Los elementos conspirativos eran muy fáciles de ubicarse y como no se trató en ningún momento de investigar por razones de respeto al camarada, la forma de pensar del personal militar, prácticamente no hubo ninguna acción, que pudiera ser motivo de preocupación. ${ }^{11}$
\end{abstract}

El 16 de septiembre la Agrupación recibió un radiograma del Comando en Jefe del Ejército ordenando el alistamiento para marchar sobre vehículos a Córdoba. ${ }^{12} \mathrm{El}$ comandante general Raviolo Audisio que se hallaba en Buenos Aires, partió esa misma mañana rumbo a Mendoza para ponerse al frente de las tropas. Al pasar por San Luis se entrevistó con el general Eugenio Arandía, Jefe del Estado Mayor del Segundo Ejército, quien le manifestó que los oficiales del comando mantenían su lealtad y fidelidad a la Constitución y a la ley.

A medianoche llegó a Mendoza y se puso al frente de la Agrupación que ya había iniciado la marcha en dirección a Córdoba. Con respecto a este acontecimiento Alberto Serú García recordaba:

Cuando la columna militar salió a San Luis yo propuse a Evans que planteara al general Lucero, con quien hablaba por teléfono a Buenos Aires, que en cada camión viajara un dirigente de civil, que se proveyera de vino a cada camión con soldados y que durante todo el trayecto a San Luis y mientras las tropas estuvieran en San Luis se programaran actividades de adhesión a Perón, al

\footnotetext{
${ }^{10}$ Alberto Serú García, ex legislador peronista, entrevista realizada en Mendoza, marzo 1991

11 Horacio Farmache, militar retirado, entrevista realizada en Mendoza, octubre de 1990.

12 Según nos relató Farmache, en menos de doce horas se trasladaron las tropas procedentes de San Juan, Uspallata, Campo de los Andes, Tupungato y San Rafael, que eran los destacamentos de montaña, a la ciudad de Mendoza. Como en aquel entonces las unidades del ejército no estaban motorizadas, mucho menos mecanizadas, eran tropas de a pie o a caballo, y como el desplazamiento tenía que hacerse con la mayor urgencia posible, se dio la orden de requisar camiones, vehículos civiles, ómnibus de empresas del medio tanto de San Juan como de Mendoza, y de esta forma se trasladó a los aproximadamente 3.000 soldados que tenía la Agrupación de Montaña Cuyo.
} 


\title{
Yamile Álvarez
}

peronismo y a la doctrina, incluso con el canto, de tanto en tanto, de la marcha peronista para tonificar al grueso de los soldados. El gobernador Evans lo planteó delante de mí al general Lucero por teléfono y el general Lucero se opuso terminantemente... Es decir desecharon mi idea. ${ }^{13}$

Durante el trayecto, Elizondo y otros oficiales revolucionarios fueron hablando con los distintos jefes para tantear sus opiniones. A media mañana del 17 de septiembre, la columna llegó a San Luis para abastecerse.

El general Raviolo Audisio con su estado mayor se estableció en la oficina del Comandante del Segundo Ejército, y allí un grupo de jefes y oficiales entre los que se hallaban los tenientes coroneles Eduardo Aguirre, Fernando Elizondo, Alberto Cabello, Juan José Avila, Porrini y López Rosas; mayores Santamaría, Blanco, Argumedo, Quiroga, Rosa Gutiérrez y el capitán Colombo, pidieron una reunión con él. Habló el teniente coronel Aguirre quien le expresó que ellos eran solidarios con el golpe de Estado y que no querían marchar a Córdoba y le pedían que se plegara a la Revolución. El general Raviolo expresó que quería conocer la opinión de cada uno de los jefes, declarándose la mayoría revolucionaria. Se mantuvieron leales los coroneles Croce, Botto y Agustoni, el teniente coronel Valentín Ugarte, el coronel Di Sisto y el teniente coronel Renato Stassi. Entonces, el general Raviolo dijo:

Señores yo en estos momentos me retiro a mi casa porque como general no puede aceptar que acá haya dos bandos. Yo soy un general y tengo la obligación de mantener la unidad espiritual de mis cuadros y subordinación al poder constitucional, como soy leal a la Constitución y la ley, observo que en este momento mi misión está terminada. Yo regreso a mi casa, me retiro del Ejército, que se haga cargo el más antiguo. ${ }^{14}$

Respecto a esta actitud y de los acontecimientos que la produjeron nos dio su opinión el teniente coronel Farmache:

\begin{abstract}
El general Raviolo Audisio era un hombre de bien y posiblemente por tener esa jerarquía moral y espiritual no optó por la medida que debía haber tomado como militar, que es haber metido presos a los que eran rebeldes. Prefirió no adoptar esa medida que posiblemente, vulneraba su sentido de camaradería y de solidaridad y su responsabilidad como comandante y facilitó que los oficiales que se habían declarados revolucionarios se hicieran cargo de la situación...

Es obvio que lo que pasó en San Luis fue consecuencia de un trabajo previo que habían hecho ciertos oficiales que estaban en una actitud revolucionaria. Pero lo que puedo asegurar es que tanto el comandante de la Agrupación de Montaña Cuyo, como los hombres que estábamos a su alrededor, uno de ellos era yo, ignorábamos en absoluto esas posturas. ${ }^{15}$
\end{abstract}

Este oficial, mientras se producía la reunión de jefes, fue protagonista del único hecho de violencia que se registró ese día en San Luis. Fue herido de bala en una pierna por el capitán Simón Severo López mientras tomaba café en una de las

\footnotetext{
13 Alberto Serú García, más de 60, ex legislador peronista, Mendoza, marzo 1991.

${ }^{14}$ Horacio Farmache, militar retirado, entrevista realizada en Mendoza, octubre de 1990.

15 Ibídem.
} 
habitaciones del comando. Posteriormente fue trasladado en una ambulancia al Hospital Militar de Mendoza.

Luego del retiro del general Raviolo Audisio, se hizo cargo del mando de las tropas el general Eugenio Arandía, quien decidió retornar con ellas a Mendoza, pero antes instauró la Revolución en Cuyo, abriendo un tercer frente contra Perón. Se instaló en San Luis el primer gobierno revolucionario provincial a cargo del coronel Carlos Trogliero y fue ocupado el Aeródromo de Villa Mercedes, base de los bombarderos pesados.

Mientras tanto el 17 de septiembre la actividad en la capital y el resto de la provincia fue normal. El gobierno provincial, comunicó a la población, a través de las emisoras locales que se hallaba constituido en pleno en el Palacio de Gobierno, en permanente contacto con el comando de represión. Por su parte el general Lagos decidió esperar el regreso de las tropas y hacerse cargo del mando aquí en Mendoza.

En la delegación regional de la CGT hubo mucho movimiento de dirigentes y afiliados que se mantuvieron en contacto con la CGT nacional y con el gobierno provincial. Decio Naranjo, dirigente gremial en aquellos días nos comentó al respecto:

\begin{abstract}
Cuando nos enteramos de que el Ejército de Cuyo volvía rebelde, nosotros nos convocamos todos en la CGT para tratar de ver si podíamos de alguna manera impedir el regreso de este Ejército, para lo cual se toman algunas medidas aisladas, como vigilar el puente de Palmira para ver si había alguna posibilidad de impedir el ingreso de las fuerzas rebeldes. La dirigencia sindical vive una eterna zozobra... Lo único posible era tratar de dinamitar el puente de Palmira para que no volvieran las tropas pero no se pudo hacer porque no se consiguieron explosivos suficientes. Las camionetas las habíamos conseguido en una repartición pública pero no habían elementos necesarios para llegar a hacer este acto. Si no, se hubiera volado. ${ }^{16}$
\end{abstract}

Entretanto, las tropas rebeldes procedentes de San Luis al mando del general Arandía llegaron al puente de Palmira al anochecer y decidieron detenerse allí para no marchar de noche y evitar cualquier ataque por parte de los leales al gobierno de Perón, ya sean civiles o militares. El general Arandía mandó a buscar al general Lagos a la ciudad de Mendoza y en el Puente de Palmira, ${ }^{17}$ a le entregó el mando. Allí esperaron hasta que amaneciera para entrar en Mendoza.

Esa madrugada se vivieron horas de gran nerviosismo en la Casa de Gobierno. Numerosos funcionarios, legisladores y políticos se hallaban en las salas contiguas al despacho del gobernador, que estaba reunido junto al vice gobernador y sus ministros. El Dr. Evans se mantenía en continuo contacto con la Jefatura de Policía, el Ministro del Interior y la Base Aérea. A las cuatro de la mañana, el gobernador y sus acompañantes abandonaron la Casa de Gobierno. Ya no volvería más a ella. El gobierno provincial no tomó ninguna medida para tratar de evitar la entrada de las

16 Decio Naranjo, dirigente gremial peronista, secretario general de la CGT regional por varios períodos, entrevista realizada en Mendoza, diciembre de 1990.

${ }^{17}$ Este puente es estratégico ya que cruza el río Mendoza y es la puerta de acceso a la ciudad capital, de allí que quedó custodiado luego del retorno de las tropas. 


\title{
Yamile Álvarez
}

tropas a Mendoza, ni organizó algún tipo de resistencia armada. Al respecto Serú García sostuvo:

\begin{abstract}
En la reunión en la Casa de Gobierno sostuve la necesidad de hacer el último esfuerzo de conversar con los jefes y con la tropa... Cuando se resolvió quien iría a esta charla, si mal no recuerdo, dijeron que fuera yo que había sido el de la moción. Yo salí en auto con un chofer de la gobernación y creo que me acompañaba el ex diputado Albino, que era el escribano de gobierno, y nos fuimos sin otro rumbo que ir en dirección al Este hasta encontrar el primer contingente militar y conversar con el jefe... No vimos a nadie. Estando por Santa Rosa vimos llegar una camioneta, una ambulancia, y el sargento que manejaba nos dijo que llevaban un herido, que lo dejaran seguir. Llevaban al capitán Farmache. Nosotros nos cansamos y perdimos un poco confianza en nuestra gestión, así que nos volvimos. ${ }^{18}$
\end{abstract}

Las tropas penetraron en la mañana del 18 de septiembre. Un piquete del Ejército ocupó posiciones en los jardines y en la explanada frente a la Casa de Gobierno. Posteriormente, llegaron más soldados para ocupar los balcones y terrazas y el edificio en construcción del Palacio de Justicia, en espera de que se hiciera cargo del gobierno el general (R) Roberto V. Nazar, designado por el general Lagos Interventor de la Provincia. El Comando Revolucionario se instaló en la compañía de comunicaciones que se hallaba ubicada en la calle Boulogne Sur Mer.

Las fuerzas militares también ocuparon la sede de la delegación regional de la CGT, ya que corrían rumores de que allí habían armas, al igual que en los gremios. Pero todas estas versiones fueron infundadas, ya que en la CGT sólo se encontró una pistola y los dirigentes se entregaron pacíficamente. ${ }^{19}$ Otro de los edificios ocupados militarmente fue el Correo Central. Al teniente coronel Cabello se le ordenó tomar la IV Brigada Aérea, cosa que hizo después de una simbólica resistencia y esto permitió establecer la comunicación aérea con Córdoba. A medida que la población se iba enterando lentamente de estos hechos, se fue volcando a las calles mediante manifestaciones callejeras. Lo hacían en vehículos o a pie y eran personas de muy diversas edades y condiciones, mujeres y hombres. Se agitaban banderas y pañuelos blancos y se expresaban vivas a la Revolución, censurando al Poder Ejecutivo Nacional.

Hubo algunos manifestantes que portaban piezas de bronce que habían estado colocadas en distintos lugares de la ciudad como homenaje al Presidente de la Nación y a Eva Perón, carteles del Partido Peronista y otros elementos que de una u otra manera tenían algún significado vinculado al peronismo. Al llegar frente al diario "Los Andes" muchos de ellos pidieron que tocaran las sirenas. Sin embargo, no todo fue tan pacífico, y algunos grupos atacaron el diario "La Libertad" produciendo daños en sus secciones de administración general y redacción y prendieron fuego a las cortinas y papeles de los locales del frente. También sufrieron

\footnotetext{
18 Alberto Serú García, ex legislador peronista, entrevista realizada en Mendoza, marzo 1991.

${ }^{19}$ El ex primer teniente Ahualli nos manifestó que el general Lagos lo envió a la CGT a investigar si allí había armas. Apresaron a la gente de la CGT empezando por el secretario general Gómez, y después de interrogarlos brevemente los dejó marcharse porque era falso que hubiera armas.
} 
daños los locales que ocupaban la UES rama masculina y femenina, los del Partido Peronista y el de la CGT. En la plaza Eva Perón fueron arrancados los letreros con su denominación y las placas de bronce que adornaban el monolito allí existente. Asimismo, fueron destruidos los bustos de Eva Perón de la Estación del Ferrocarril General San Martín, en el Barrio Cívico, y en la Municipalidad de Godoy Cruz.

Aproximadamente al mediodía el comando revolucionario a cargo del Gobierno, tomó posesión de la estación de radio LRA que realizó transmisiones bajo la denominación de "Radio Ejército de Los Andes" y a través de ella se difundieron durante el día informaciones, proclamas y advertencias en relación a lo que acontecía en Cuyo. Una de estas proclamas sostenía:

\begin{abstract}
Las fuerzas del $2^{\circ}$ Ejército vienen a traer la libertad, entendiéndose por libertad entre otras cosas lo siguiente: queremos Fuerzas Armadas donde no se inmiscuya la política, y no como ahora, donde se imparte y se obliga a acatar la doctrina de un partido político so pena de la baja, si se pretende dudar tan siquiera, de todo lo que interesadamente se dice. Por escuelas sin política tendenciosa; porque no se obligue a los empleados públicos a afiliarse a ningún partido, sino que cada uno tenga sus propias convicciones, sin demostrarlas en su puesto; por la libertad de nuestros camaradas que pese a la ley de amnistía sancionada por el Congreso aún continúan en las cárceles junto con los peores delincuentes. ${ }^{20}$
\end{abstract}

La asunción del general Nazar como interventor Provincial se llevó a cabo al anochecer. Cabe destacar que el general Nazar era amigo personal del general Perón con quien había estado en Italia. El general Franklin Lucero sostiene que:

Tuvo libre acceso a la Presidencia de la Nación; planteaba directamente sus inquietudes políticas y la de sus amigos al general Perón, era el verdadero gestor de Mendoza y obtuvo para sus familiares positivos beneficios. ${ }^{21}$

Según sus familiares, estaba retirado desde hacía un año porque estando como jefe en Neuquén había dado buen trato a los oficiales que estaban bajo arresto. Desde hacía tiempo estaba en contacto con los revolucionarios, principalmente con el teniente coronel Elizondo. Sin embargo, días antes de la Revolución, pidió a un político mendocino que iba a entrevistarse con Perón, que le recordara al general su promesa de nombrarlo embajador en el Paraguay.

En la bibliografía referida a la "Revolución del 55" se habla de la existencia en Córdoba y en Buenos Aires de "Comandos Civiles" que actuaron durante esos días. En Mendoza también los hubo. Algunos de estos grupos se habían formado antes de que estallase la revolución en previsión de una posible guerra civil y estaban integrados en su mayoría por políticos de la oposición. Pero a partir de la noche del 18 de setiembre y en los días subsiguientes, se presentaron como voluntarios gentes de muy diversos sectores políticos y culturales. Los lugares de concentración eran

\footnotetext{
${ }^{20}$ Los Andes, Mendoza, 19/09/1955, p.4

${ }^{21}$ Franklin Lucero. El precio de la lealtad, injusticias sin precedentes en la tradición argentina. Buenos Aires, Propulsión, 1959. p. 154.
} 


\title{
Yamile Álvarez
}

las sedes de los partidos políticos, el comando Revolucionario y la sastrería militar. Aquí impartía las órdenes el mayor Carlos Elías Villanueva. Se les repartió garibaldinas y fusiles "Mauser" y la función de estos grupos civiles a cuyo frente iba un oficial y suboficial, era la de ayudar y cooperar con las tropas previendo un posible ataque leal. Se los envió a recorrer los departamentos y a vigilar los lugares claves, como por ejemplo, la estación de tranvías, la usina de Alvarez Condarco, la usina eléctrica de la calle San Martín, etc. En caso de que hubiera disturbios en esos lugares debían defenderlos hasta que llegaran las tropas del Ejército. Se destacan, entre las misiones en las que participaron, la toma de la delegación de la Policía Federal a cargo del mayor Rufino Ortega con el apoyo de numerosos civiles aportados especialmente por el radicalismo, la ocupación de la dependencia policial de la provincia, en donde el jefe designado por el comando revolucionario, capitán (R) Miguel Ángel Pott Godoy sustituyó al entonces jefe Roberto Castro Villalba. Sobre este tema el dirigente demócrata Roberto Videla Zapata nos refería:

\begin{abstract}
a mí me tocó junto con mi cuñado, Alberto Guiñazú, que era fiscal federal y que también se había ido a ofrecer y con otro más que no recuerdo el nombre, ir a recorrer y establecer vigilancia sobre la zona de Maipú, Gutiérrez hasta la destilería, así que estuvimos toda la noche dando vueltas a ver si se veía alguna cosa rara, porque llamaba la atención que habiendo tenido tanta mayoría de votos siempre acá Perón, y teniendo la prensa, no se produjera ninguna reacción. ${ }^{22}$
\end{abstract}

Las emisoras radiales mendocinas fueron otro de los objetivos asignados a estos civiles; una de ellas LV10 Radio de Cuyo, situada en la calle Las Heras, fue tomada por un grupo encabezado por el Dr. Dante D'Angela Patrucco. La acción de los comandos civiles se desarrolló durante los primeros días de la Revolución y terminó a los pocos días, cuando se restableció la normalidad. ${ }^{23}$

La Revolución triunfó en Mendoza el 18 de septiembre, mucho antes incluso que en el resto del país donde la situación de los rebeldes era más que comprometida. Creemos que esta circunstancia fue trascendental para el triunfo de la revolución a nivel nacional, ya que desde el punto de vista militar le restaba un importante aporte en tropas y materiales a las fuerzas de la represión, abría un tercer frente revolucionario que comprendía un parte grande e importante del territorio nacional con frontera abierta a otro país y permitía, en caso de que la situación de Córdoba se agravase, la evacuación por vía aérea de esa guarnición. Pero además de las consideraciones de tipo militar, el teniente coronel Horacio Farmache hizo hincapié en el impacto moral que la defección de Cuyo debió haber producido en el presidente Perón:

Yo creo que Mendoza tuvo mucha gravitación no por el hecho militar en sí, sino porque gravitó mucho sobre la decisión de Perón. Perón presentó la renuncia no por verse forzado por las circunstancias de orden militar. En ese momento un 70

\footnotetext{
22 Roberto Videla Zapata, dirigente demócrata. Entrevista realizada en Mendoza, octubre de 1990.

${ }^{23}$ Los datos obtenidos para reconstruir la existencia y el accionar de los comandos civiles fueron aportados por algunos de sus integrantes y el diario local Proceso del 6 de octubre de 1955.
} 
u $80 \%$ del ejército era leal al gobierno constitucional. Los que se habían sublevado no pasaban de ser un porcentaje menor y sobre todo radicado en el cuadro de oficiales. El resto de los oficiales, sobre todo la suboficialidad del ejército y la tropa, seguía siendo leal a Perón.

Yo creo que gravitó no sólo por el hecho militar en sí, sino porque en ese momento Perón, que tenía gran afecto por las tropas de montaña, que dentro de las tropas de montaña tenía amigos que quería mucho como el general Nazar, el general Raviolo, los coroneles Plantamura, Aguirre, esos oficiales habían sido amigos de él y él los había apreciado y hasta protegido dentro de su carrera, y claro, Raviolo tuvo una conducta digna distinta a la de otros, pero otros se pasaron directamente al bando revolucionario y eso deber haber golpeado mucho sobre Perón, desde el punto de vista moral y espiritual. ${ }^{24}$

\section{Gobierno nacional provisorio en Mendoza}

El 19 de septiembre por la mañana llegó a Mendoza el ayudante del general Lonardi, Mayor Juan F. Guevara, portando una carta del jefe de la revolución en donde le pedía al general Lagos, que le enviara toda la infantería, ametralladoras y morteros que pudiera ya que su situación en Córdoba era muy comprometida. Pero el general Lagos contaba con muy pocos hombres en Mendoza, los cuales le eran indispensables para mantener el orden en la ciudad, mientras que el resto de las tropas estaban repartidas entre San Juan y San Luis. De todas formas decidió quitar hombres de cada compañía para reunir un batallón de doscientos hombres que se embarcó hacia Córdoba esa noche a las órdenes del capitán Januzzi.

Esa misma mañana el general Lagos recibió la visita del representante de la Marina de Guerra, capitán de fragata de Carlos García Favre, quien le propuso organizar en Mendoza un Gobierno nacional provisorio que obtuviera reconocimiento internacional. Las razones por él sostenidas eran que, como la escuadra nacional se había sublevado y había establecido el bloqueo del Río de la Plata y de todos lo puertos argentinos, este bloqueo frente a las potencias internacionales era ilegal y sólo podía ser regularizado con la constitución de un gobierno revolucionario que asumiera la condición de beligerante, caso contrario, el bloqueo se podía considerar un acto de piratería e incluso provocar alguna intervención extranjera. El mismo general Lonardi, poco después, pidió al general Lagos la constitución de este gobierno en Mendoza. Consideraba que dada su precaria situación iba a ser derrotado en breve y en ese caso, Lagos debía continuar la resistencia armada desde Mendoza, donde existían las condiciones necesarias para poder sostenerse durante largo tiempo, debido a que poseía una extensa frontera internacional abierta. Incluso, de ser necesario, se pensó en separar la región de Cuyo del resto del país. El general Lagos encargó esta delicada misión a su asesor legal Bonifacio del Carril, que se conectó con el Dr Vera Vallejo explicándole claramente la situación. Este dirigente llamó a las dos principales figuras demócratas de ese momento que eran Carlos Aguinaga y Raúl Benegas. Sobre este tema Carlos Aguinaga nos relató:

${ }^{24}$ Horacio Farmache, militar retirado, entrevista realizada en Mendoza, octubre de 1990. 


\section{Yamile Álvarez}

Cuando la situación de Córdoba peligraba y se creía que estaba a punto de caer... Del Carril nos pidió que integráramos el gobierno nacional que se establecería en Mendoza. Nosotros dijimos que queríamos que si el gobierno se instalaba en Mendoza debía ser también con dirigentes de partidos opositores del resto del país y porque el ofrecimiento era para que fueran todos mendocinos. ... nosotros planteamos que en los viajes que se hacían a Córdoba para llevar ayuda, se trajeran algunos dirigentes de Córdoba donde los partidos opositores al peronismo tenían un sector muy importante... Cuando a mí me mandó a llamar al Dr. Vera Vallejo, yo le plantee de entrada el problema de que se tenía que hacer con toda la oposición y especialmente con los radicales, y con ese motivo Vera Vallejo invitó a los dirigente radicales Leopoldo Suárez y Alfredo Vítolo a las reuniones que se realizaban conmigo y con Raúl Benegas. ${ }^{25}$

Todos aceptaron el ofrecimiento pero dicho gobierno no alcanzó a constituirse ya que Perón abandonó el gobierno pocas horas después. No se redactó ningún documento o acta sobre estas conversaciones, pero dos días después los cuatro dirigentes enviaron una carta de apoyo a la Revolución al general Lagos. Dicha carta fue redactada de puño y letra por el propio Carlos Aguinaga, pero los radicales se negaron a que se diera a publicidad. Es la única prueba escrita que existe sobre este plan inconcreto de constituir un gobierno nacional provisorio en Mendoza. En ella, entre otras cosas, expresan:

La revolución en Cuyo ha contribuido decisivamente en el resultado glorioso de la jornada, y el $2^{\circ}$ Ejército bajo su mando, ha podido utilizar con verdad el nombre de Ejército de los Andes.

Nosotros, que hemos tenido el honor, en un momento difícil de actuar en la misión que se nos encomendara, por encima de las diferencias ideológicas y unidos por esos altos ideales, que son comunes a todos los argentinos, y que se manifiestan espontáneamente cuando la Patria pareciera exigirlo con más intensidad, debemos expresarle nuestro reconocimiento por la confianza que significó la demanda y que cumplimos, también, por la confianza que teníamos en los móviles de la revolución. ${ }^{26}$

Al delegar Perón sus funciones en una Junta Militar, la constitución de un gobierno revolucionario dejó de ser necesaria, por lo que Del Carril se reunió esa misma tarde con Aguinaga, Benegas, Suárez y Vitoló para expresarles estas consideraciones. Todos coincidieron al respecto y ofrecieron seguir actuando juntos con la participación de representantes del Partido Socialista y Demócrata Progresista para asesorar al gobierno de la Revolución en lo que fuera necesario. De esta manera quedó constituida la primera Junta Consultiva Provincial, la cual tenía como sede de sus reuniones la Legislatura, aunque careció de carácter oficial.

Esa tarde cuando se conocieron las noticias procedentes de Buenos Aires, gran cantidad de gente de todas las edades se volcaron a las calles céntricas para expresar su alegría portando banderas y leyendas con fases alusivas al movimiento revolucionario.

Estas manifestaciones se extendieron durante varias horas, sonaron las sirenas del diario "Los Andes" y repiquetearon las campanas de la Iglesia de la Compañía de

${ }^{25}$ Carlos Aguinaga, dirigente demócrata. Entrevista realizada en Mendoza, septiembre de 1990.

${ }^{26}$ Carta enviada al general Lagos el 21 de septiembre de 1955. Gentileza Dr. Carlos Aguinaga. 
Jesús, pero todo se desarrolló sin inconvenientes. Casi al mismo tiempo que eran exteriorizadas estas manifestaciones de júbilo, se produjo el único acto de violencia registrado en Mendoza durante estos días. La crónica periodística nos dice lo siguiente:

hacia el final de la tarde, algunas personas civiles adoptaron una actitud homicida en contra de hombres que vestían el uniforme del Ejército. Esto ocurrió en la manzana que ocupan en block el Plaza Hotel, el Casino y el teatro Independencia. El sorpresivo ataque con armas de fuego, que partió de ese inmueble, causó en el primer momento un soldado muerto y un oficial herido. Las tropas que en ese momento se hallaban allí o circulaban por el lugar tomaron prestamente posición de defensa, mientras los atacantes se atrincheraban en parte del edificio y del pequeño jardín del casino que da a la calle Sarmiento. Eran, al parecer, empleados del casino y del Plaza Hotel, haciendo las tropas una descarga de ametralladoras. Todo hacía presumir que los atacantes se proponían mantener su actitud y continuar atacando con armas de fuego. Entonces comenzaron a afluir en torno de la manzana y en sus proximidades otras fuerzas: del ejército, aeronáutica y policía, con algunos camiones provistos de ametralladoras y otras armas.

... El ejército insistió largamente con altavoces instando a la rendición. Alrededor de las 20.30 se escucharon los últimos disparos. Si bien se sabe que los revoltosos fueron completamente reducidos, se ignora si hubo otros heridos o no. ${ }^{27}$

El oficial herido fue el teniente Salice. Corrieron varios rumores sobre este hecho, se llegó a decir que era un contra golpe peronista, o que debido a la proximidad de la CGT, los obreros eran los responsables. Pero resultaron ser rumores infundados. Uno de nuestros testigos, el ex teniente Ahualli, sostuvo que quizás el tiroteo fue provocado por las mismas tropas al querer apoderarse del edificio del Casino en grupos separados y debido a la confusión reinante, se habría producido un intercambio de disparos. Los heridos en este incidente fueron trasladados al Hospital Militar.

Ese mismo día, se realizaron las primeras detenciones de ex-funcionarios del régimen depuesto.

A partir del 20 de septiembre el interventor militar general Roberto Nazar inició la organización de su gabinete, cuyos miembros civiles pertenecían en su mayoría, a los partidos Demócrata y Radical. También por decreto cesaron en sus funciones los intendentes municipales y consejos deliberantes. En los días siguientes se declaró en comisión al poder judicial a fin de reorganizarlo. El 23 de septiembre a la noche Nazar dirigió su primer mensaje radial a los mendocinos. En él señaló que los objetivos de la revolución eran "reestablecer el amplio ejercicio de los derechos individuales, asegurar el normal funcionamiento de las instituciones republicanas y preparar el camino para reestablecer la vigencia plena de un auténtico orden constitucional y legal". También sostuvo que la Revolución Libertadora se había hecho porque "con el pretexto de realizar la justicia social se han vulnerado todos los otros derechos, tan importantes como aquellos". ${ }^{28}$ Y resaltó que la justicia social

\footnotetext{
${ }^{27}$ Los Andes, Mendoza, 20 /09/ 1955, p 2.

${ }^{28}$ Los Andes, Mendoza, 24/09/1955, p.3
} 


\section{Yamile Álvarez}

era un derecho de los obreros, por lo tanto "no crean pues, los trabajadores, que la justicia social ha sido dádiva de un hombre por las masas, porque las masas los han ganado por su propia acción". A lo largo de todo su discurso, el énfasis estuvo puesto en el restablecimiento de la libertad en todos los órdenes de la sociedad.

El general Nazar estuvo a cargo de la intervención federal hasta el 20 de noviembre de 1955, en que presentó su renuncia. En su lugar fue designado Interventor el general Héctor Ladvocat.

\section{Conclusión}

La Revolución Libertadora, que puso fin al gobierno de Juan D. Perón, marcó un punto de inflexión en nuestra historia, ya que dio inicio a un período de gran inestabilidad política e institucional caracterizado por la proscripción del peronismo.

En Mendoza la revolución fue llevada a cabo por civiles pertenecientes a los partidos demócrata y radical que desde hacía tiempo mantenían reuniones, y por un puñado de oficiales de la Agrupación de Montaña Cuyo dirigidos por el general Lagos, que lograron revertir la lealtad inicial del regimiento y convertirlo en revolucionario.

Probablemente por esto y el hecho de que en Mendoza los meses previos transcurrieron con tranquilidad, es que la dirigencia tanto política como sindical oficialista fue sorprendida por el estallido del movimiento y no hubo ningún atisbo de resistencia, ni actos de violencia.

El 18 de septiembre la revolución ya había triunfado en Mendoza mucho antes que en el resto del país. Considero que este prematuro triunfo fue decisivo para el éxito definitivo de la revolución, ya que desde el punto de vista militar restó fuerzas a la represión del levantamiento en Córdoba, abrió un nuevo y extenso foco rebelde con frontera internacional y afectó moralmente al Presidente, según uno de nuestros testigos, dada su predilección por los montañeses.

Prueba de la importancia del levantamiento provincial es el hecho de que, en los momentos críticos, se pensó en constituir un Gobierno Nacional Provisorio en Mendoza. La finalidad de esta creación era lograr a la brevedad posible el reconocimiento internacional del movimiento. Los testimonios orales de algunos dirigentes políticos que jugaron un papel decisivo en este suceso, nos han permitido obtener una valiosa información al respecto. Por estas fuentes sabemos que este Gobierno Nacional Provisorio, iba a estar integrado por dos demócratas (Aguinaga y Benegas) y por dos radicales (Suárez y Vítolo). En definitiva, no se constituyó debido al alejamiento de Perón. De todos modos sus eventuales integrantes pasaron a formar de la primera Junta Consultiva provincial, asesora del gobierno del general Nazar.

En lo que respecta a los objetivos del movimiento, desde el principio los militares revolucionarios, a través de las proclamas, y luego en el primer discurso del interventor federal, manifestaron sus intenciones de restablecer la libertad en todos 


\section{Aportes para una historia de la Revolución Libertadora en Mendoza}

sus aspectos y los derechos individuales que, a su entender, habían sido violados por el régimen depuesto.

\section{Bibliografía}

Laura Benadiba y Daniel Plotinsky. De entrevistadores y relatos de vida. Introducción a la Historia Oral. Buenos Aires, Imago Mundi, 2005.

Omar Cueto y otros. Historia de Mendoza. Mendoza, Los Andes, 1995.

Pedro S. Martínez. Historia de Mendoza. Buenos Aires, Plus Ultra, 1979.

Bonifacio Del Carril. Crónica interna de la Revolución Libertadora. Buenos Aires, Emecé, 1959.

Diario Los Andes. Cien años de vida mendocina. Mendoza, 1982.

Eduardo García. Yo fui testigo. Buenos Aires, Luis Lascerre y Cía. S.A. Editoras, 1971. Alicia Gartner. Historia Oral, memoria y patrimonio. Aportes para un abordaje pedagógico. Buenos Aires, Imago Mundi, 2015.

Junta de Estudios Históricos de Mendoza. Historia Contemporánea de Mendoza a través de sus gobernadores. T I (1932-1966). Mendoza, 1996.

Franklin Lucero. El precio de la lealtad, injusticias sin precedentes en la tradición argentina. Buenos Aires, Propulsión, 1959.

Benito Marianeti. Las luchas sociales en Mendoza. Mendoza, Editorial Cuyo, 1970.

Arturo Roig y otros, (compiladores). Mendoza, a través de su historia. Mendoza, Book, 2004.

Dora Schwarzstein. "El lugar de las fuentes orales en los archivos: una cuestión en debate". Estudios Sociales, N²2-23, Año XII. Santa Fe, 2002, pp 11-22.

\section{Periódicos}

"Los Andes", Mendoza. Ediciones correspondientes al año 1955.

"La Libertad", Mendoza. Ediciones correspondientes al año 1955.

"La Palabra", Mendoza. Ediciones correspondientes al año 1955.

"La Tarde", Mendoza. Ediciones correspondientes al año 1955.

"Proceso", Mendoza, 6 de octubre de 1955.

\section{Fuentes Orales}

Dr. Carlos Aguinaga.

Vicecomodoro (R) Ricardo Ahualli.

Teniente coronel (R) Horacio Farmache.

Sr. Decio Naranjo.

Dr. Alberto Serú García.

Dr. Robe

Recibido: 03/03/2016

Evaluado: 01/04/2016

Versión Final: 20/04/2016 